\title{
Murut language variation in Sipitang Sabah
}

\begin{abstract}
In general, this study aims to examine the variation of Malay language among the people in Sabah Sipitang is done because of differences bachelor's Sabah Malay dialect, the ambiguity of language and vocabulary differences between the races. Generally, varieties of Malay analyzed using the framework nature of the lexicon, Malay style changes were analyzed based on the theory of substrate, thereby developing a variety of Malay culture. In particular, two objectives, namely to identify and analyze varieties of Malay society Sipitang in Sabah. Samples of the study were Sabah natives of Murut residents of Sipitang district. This study uses the Asma Haji Omar (2008) lexicon character framework by focusing on the formation of lexical texts consisting of standard languages, dialects, bilinguals and bilinguals. Subsequent studies conducted in this field involved 40 respondents comprising people in Sipitang district. As most speakers of the indigenous people of Sabah Sabah Malay language as a second language, they tend to borrow the words of their native language. Of particular importance in this study were the variation of the regions or regions because differences in the use of words and expressions could be detected from the five-person conversation studied. Next, the results of this study researchers found that respondents from five races in Sipitang is a very active group to shape variation Malay Sabah. The essence of the study showed that the dialects of Brunei and Kedayans very influential in lexical Malay Sabah Malay Sabah is a branch of the Brunei Malay vernacular that has received regional influence and developed into a communication between people with pidgin features.
\end{abstract}

Keyword: Varation; Malay language; Community; Sipitang; Lexicon character framework. 